\title{
Clinical Outcome after Thrombectomy in Patients with Stroke with Premorbid Modified Rankin Scale Scores of 3 and 4: A Cohort Study with 136 Patients
}

\author{
(D)F. Seker, (D). Pfaff, (D) S. Schönenberger, (D). Herweh, DS. Nagel, DP.A. Ringleb, (D) M. Bendszus, and (D) M.A. Möhlenbruch
}

\begin{abstract}
BACKGROUND AND PURPOSE: We aimed to analyze the clinical outcome after mechanical thrombectomy in patients with premorbid $\mathrm{mRS} 3$ and 4 because there are currently no data on this patient group.
\end{abstract}

MATERIALS AND METHODS: Between January 2009 and November 2017, all patients with premorbid mRS 3 or 4 undergoing mechanical thrombectomy due to anterior circulation stroke were selected. Good outcome was defined as a clinical recovery to the status before stroke onset (ie, equal premorbid mRS and mRS at 90 days). In addition, mortality at discharge and at 90 days was analyzed.

RESULTS: One hundred thirty-six patients were included, of whom 81.6\% presented with premorbid mRS 3; and 18.4\%, with premorbid mRS 4; $24.0 \%$ of patients with premorbid mRS 4 achieved clinical recovery compared with $20.7 \%$ of patients with premorbid mRS $3(P=$ .788). However, the proportion of hospital mortality and mortality at 90 days was nonsignificant, but markedly higher in patients with premorbid mRS 4. Multivariate analysis identified low NIHSS scores (OR, 0.92; 95\% Cl, 0.85-0.99; $P=.040$ ), high ASPECTS (OR, 1.45; $95 \% \mathrm{Cl}$, 1.02-2.16; $P=.049)$, and TICl 2b-3 (OR, 7.11; 95\% Cl, 1.73-49.90; $P=.017)$ as independent predictors of good outcome.

CONCLUSIONS: Good outcome in patients with premorbid mRS 3 and 4 is less frequent compared with premorbid mRS $0-2$. Nevertheless, about $20 \%$ of the patients return to their premorbid mRS, which may justify endovascular treatment. The most important predictor of good outcome is successful recanalization.

ABBREVIATION: $M T=$ mechanical thrombectomy

$\mathrm{T}$ he mRS is a commonly used outcome measure in stroke treatment (Table 1). ${ }^{1}$ In addition, it is also used to assess the premorbid/prestroke disability of patients with stroke. Most randomized controlled trials on mechanical thrombectomy (MT) published in recent years excluded patients with premorbid mRS $>1 .^{2}$ Only the Endovascular Therapy Following Imaging Evaluation for Ischemic Stroke 3 (DEFUSE-3) included patients with premorbid mRS $0-2 .{ }^{3}$ Therefore, the American Heart Association/American Stroke Association briefly addressed this issue in their latest guidelines, stating that MT in patients with premorbid $\mathrm{mRS}>1$ has uncertain benefits and further randomized controlled trials are necessary. ${ }^{4}$

Nevertheless, many stroke centers regularly perform MT in patients with premorbid mRS 2 (ie, in patients with slight disability but functional independence before stroke onset). However,

Received May 21, 2018; accepted after revision November 7

From the Departments of Neuroradiology (F.S., J.P., C.H., M.B., M.A.M.) and Neurology (S.S., S.N., P.A.R.), Heidelberg University Hospital, Heidelberg, Germany.

Please address correspondence to Markus A. Möhlenbruch, MD, Im Neuenheimer Feld 400, 69120 Heidelberg, Germany; e-mail: markus.moehlenbruch@med.uni-heidelberg.de

http://dx.doi.org/10.3174/ajnr.A5920

there are uncertainties about the efficacy of thrombectomy in patients with moderate and moderately severe disability (ie, premorbid mRS 3 and 4). To our knowledge, there are no randomized controlled trials or cohort studies addressing this issue. Therefore, we analyzed clinical outcomes of patients with anterior circulation stroke and premorbid mRS 3 and 4 undergoing MT at our comprehensive stroke center.

\section{MATERIALS AND METHODS Patient Selection}

Between January 2009 and November 2017, all patients with stroke undergoing MT at our institution were prospectively collected in a stroke data base. For these patients, we performed a single-center, observational, retrospective cohort study. Inclusion criteria were the following: 1) occlusion of the intracranial internal carotid artery or M1 or M2 segment of the middle cerebral artery, and 2) premorbid mRS 3 or 4 . Our institutional review board approved this study. Informed consent was waived.

\section{Treatment}

The decision for treatment was made in consensus between the neurologist and neuroradiologist on duty, mostly depending on 
the imaging findings and the probable or explicit patient preference. Patients received intravenous thrombolysis, if eligible. Patients underwent MT with the intention to achieve TICI $2 \mathrm{~b}-3$.

\section{Image Analysis}

The baseline ASPECTS was determined on either nonenhanced CT scans or diffusion-weighted images before MT by a radiologist. The occlusion site was determined on digital subtraction angiograms. Successful recanalization was defined as TICI $2 \mathrm{~b}-3$ on the final angiogram.

\section{Outcome Measures}

The primary outcome parameter was good clinical outcome defined as a clinical recovery to the status before stroke onset (ie, premorbid mRS and mRS scores at 90 days were equal). Poor outcome was defined as any worsening of the mRS score at 90 days. Secondary outcome parameters were hospital mortality and mortality at 90 days.

\section{Table 1: Modified Rankin Scale}

\begin{tabular}{|c|c|}
\hline Score & Description \\
\hline 0 & No symptoms at all \\
\hline 1 & $\begin{array}{l}\text { No significant disability despite symptoms: able to } \\
\text { carry out all usual duties and activities }\end{array}$ \\
\hline 2 & $\begin{array}{l}\text { Slight disability: unable to carry out all previous activities, } \\
\text { but able to look after own affairs without assistance }\end{array}$ \\
\hline 3 & $\begin{array}{l}\text { Moderate disability: requiring some help, but able to } \\
\text { walk without assistance }\end{array}$ \\
\hline 4 & $\begin{array}{l}\text { Moderately severe disability: unable to walk without } \\
\text { assistance and unable to attend own bodily needs } \\
\text { without assistance }\end{array}$ \\
\hline 5 & $\begin{array}{l}\text { Severe disability: bedridden, incontinent, and requiring } \\
\text { constant nursing care and attention }\end{array}$ \\
\hline 6 & Death \\
\hline
\end{tabular}

Originally published in van Swieten J, Koudstaal P, Visser M, et al. "Interobserver agreement for the assessment of handicap in stroke patients." Stroke 1988;19:604-07.

Table 2: Patient characteristics

\begin{tabular}{|c|c|c|c|c|}
\hline & Total $(n=136)$ & $\begin{array}{l}\text { Good Outcome } \\
\qquad(n=29)\end{array}$ & $\begin{array}{l}\text { Poor Outcome } \\
\qquad(n=107)\end{array}$ & $P$ Value ${ }^{a}$ \\
\hline Age (mean) (SD) & $80.6(10.1)$ & $79.5(13.2)$ & $81.0(9.2)$ & .585 \\
\hline Female (No.) (\%) & $90(66.2)$ & $20(69.0)$ & $70(65.4)$ & .827 \\
\hline Diabetes (No.) (\%) & $34(25.0)$ & 5 (17.2) & $29(27.1)$ & .340 \\
\hline Hypertension (No.) (\%) & $102(75.0)$ & $21(72.4)$ & 81 (75.7) & .809 \\
\hline Arrhythmia (No.) (\%) & $84(61.8)$ & $19(65.5)$ & $65(60.7)$ & .674 \\
\hline Coronary heart disease (No.) (\%) & $41(30.1)$ & $8(27.6)$ & $33(30.8)$ & .822 \\
\hline Hypercholesterolemia (No.) (\%) & $41(30.1)$ & $8(27.6)$ & $33(30.8)$ & .822 \\
\hline Premorbid mRS (No.) (\%) & & & & .719 \\
\hline 3 & $111(81.6)$ & $23(79.3)$ & $88(82.2)$ & \\
\hline 4 & $25(18.4)$ & $6(20.7)$ & $19(17.8)$ & \\
\hline Baseline NIHSS (median) (IQR) & 18 (15-22) & 15 (12-19) & $19(15-23)$ & .009 \\
\hline ASPECTS (median) (IQR) & $9(8-10)$ & $10(9-10)$ & $9(8-10)$ & .051 \\
\hline Intravenous thrombolysis (No.) (\%) & $61(44.9)$ & $13(44.8)$ & $48(44.9)$ & 1.000 \\
\hline Onset-to-groin (median) (IQR) & $240(180-344)$ & $232(182-280)$ & $247(180-357)$ & .250 \\
\hline Groin-to-TICI (median) (IQR) & $75(41-108)$ & $63(32-97)$ & 77 (46-117) & .142 \\
\hline \multicolumn{5}{|l|}{ Occlusion site (No.) (\%) } \\
\hline ICA & $31(22.8)$ & $2(6.9)$ & $29(27.1)$ & .024 \\
\hline Ml & $78(57.4)$ & $15(51.7)$ & $63(58.9)$ & .530 \\
\hline $\mathrm{M} 2$ & $30(22.1)$ & $12(41.4)$ & $18(16.8)$ & .010 \\
\hline $\mathrm{TICl} 2 \mathrm{~b}-3$ & $103(75.7)$ & $27(93.1)$ & $76(71.0)$ & .014 \\
\hline
\end{tabular}

Note:- $I Q R$ indicates interquartile range.

${ }^{a}$ Comparison between patients with good and poor outcomes.

\section{Statistical Methods}

R Version 3.4.3 and RStudio Version 1.1.414 (RStudio; https:// www.rstudio.com/) were used for statistical analysis. Numeric baseline characteristics were described in medians and interquartile ranges or means and SDs. Patients achieving good clinical outcome were compared with those with poor outcome in a univariate analysis. All variables with $P<.1$ were included in a multivariate binary logistic regression analysis to identify independent predictors of good clinical outcome. Comparisons between groups were performed using Student $t$ tests or the Mann-Whitney $U$ test for continuous data and the Fisher exact test for categoric variables. The Kruskal-Wallis test was used for group comparisons. A $P$ value $<.05$ was considered statistically significant.

\section{RESULTS}

Of 1223 patients within the above-mentioned timeframe who underwent MT, a total of 136 consecutive patients (11.1\%) met the inclusion criteria of this study. Of these, 111 patients $(81.6 \%)$ presented with a premorbid mRS of 3 and 25 patients (18.4\%) presented with a premorbid mRS of 4 . The mean age of our cohort was $80.6 \pm 10.1$ years.

Of these 136 patients, $12(8.8 \%)$ were treated with aspiration only, $111(81.6 \%)$ were treated using stent retrievers under proximal aspiration, and $13(9.6 \%)$ were treated with aspiration attempts and stent-retriever attempts under proximal aspiration.

\section{Good-versus-Poor Outcome}

In our cohort, $21.3 \%$ achieved good clinical outcome-that is, the $\mathrm{mRS}$ at 90 days after stroke onset was the same as the premorbid $\mathrm{mRS}$. First, we compared patients achieving good clinical outcome with those achieving poor outcome (78.7\%). Age, proportion of risk factors, premorbid mRS, rate of intravenous thrombolysis treatment, and time from onset to groin puncture and from groin puncture to TICI were similar in both groups (Table 2).

Multivariate analysis identified low NIHSS scores (OR, 0.92; 95\% CI, 0.85-0.99; $P=.040)$, high ASPECTS (OR, 1.45; 95\% CI, 1.02-2.16; $P=.049)$, and TICI 2b-3 (OR, 7.11; 95\% CI, 1.73-49.90; $P=.017)$ as independent predictors of good clinical outcome. The occlusion site was not an independent predictor. Nonetheless, patients with good outcome had a significantly lower rate of ICA occlusion (6.9\% versus $27.1 \%, P=.024)$ and a significantly higher rate of M2 occlusion (41.4\% versus $16.8 \%, P=.010$ ). The proportion of M1 occlusions was nonsignificantly smaller in patients with good outcome $(51.7 \%$ versus $58.9 \%, P=.530)$ (Table 3).

\section{Premorbid mRS 3 versus 4}

Finally, we compared clinical outcomes in patients with premorbid mRS 3 and 4 . The rate of successful recanalization was similar in both groups. Ninety-day mRS was significantly higher in patients with 
Table 3: Multivariate analysis_-independent predictors of good outcome

\begin{tabular}{lcc}
\hline & Odds Ratio $(95 \% \mathrm{CI})$ & Adjusted $\boldsymbol{P}$ Value \\
\hline Baseline NIHSS & $0.92(0.85-0.99)$ & .040 \\
ASPECTS & $1.45(1.02-2.16)$ & .049 \\
ICA occlusion & $0.31(0.04-1.30)$ & .152 \\
M2 occlusion & $2.35(0.86-6.52)$ & .097 \\
TICl 2b-3 & $7.11(1.73-49.90)$ & .017 \\
\hline
\end{tabular}

Table 4: Comparison of outcome in patients with premorbid mRS 3 and 4

\begin{tabular}{|c|c|c|c|}
\hline & $\begin{array}{c}\text { Premorbid } \\
\text { mRS } 3 \\
\text { (n=111) }\end{array}$ & $\begin{array}{c}\text { Premorbid } \\
\text { mRS } 4 \\
(n=25)\end{array}$ & $P$ Value \\
\hline TICl 2b-3 (No.) (\%) & $85(76.6)$ & $18(72.0)$ & .614 \\
\hline 90-Day mRS (median) (IQR) & $5(3.5-6)$ & $6(4-6)$ & $<.001$ \\
\hline Good outcome (No.) (\%) & $23(20.7)$ & $6(24.0)$ & .788 \\
\hline Hospital mortality (No.) (\%) & $17(15.3)$ & $6(24.0)$ & .231 \\
\hline Mortality at 90 days (No.) (\%) & $52(46.8)$ & $16(64.0)$ & .183 \\
\hline
\end{tabular}

premorbid mRS 4 compared with mRS 3 (median mRS of 6 versus mRS 5, $P<.001)$. The proportion of good outcome was slightly but nonsignificantly higher in patients with premorbid mRS 4 (24.0\% versus $20.7 \%, P=.7877)$. Hospital mortality and mortality at 90 days were nonsignificantly but markedly higher in patients with premorbid mRS 4 (24.0\% versus $15.3 \%, P=.231$; and $64.0 \%$ versus $46.8 \%, P=.183$ ) (Table 4 ).

\section{DISCUSSION}

In this study, we analyzed clinical outcome in a stroke cohort that has been excluded from previous randomized controlled trials on neurothrombectomy: patients with stroke with moderate and moderately severe premorbid disability.

As a main finding, about one-fifth of our cohort achieved good clinical outcome: These patients returned to their prestroke condition 90 days after stroke onset without the need for further assistance or additional costs. Indeed, worsening of clinical status is associated with increasing health care costs. ${ }^{5}$ Dewilde et al, ${ }^{6}$ for instance, report that mRS 4 at 90 days after stroke onset was associated with significantly higher care costs compared with mRS 3 ( $\$ 4008$ versus $\$ 1639, P<.001$ ). Therefore, MT can prevent an increase of long-term health care costs in patients with elevated premorbid mRS.

The relatively low rate of good outcome compared with the results of thrombectomy in premorbid mRS 0-2 might be attributed to old age and age-related frailty. ${ }^{7}$ While mean age in our cohort was 80.6 years, median age in the Highly Effective Reperfusion evaluated in Multiple Endovascular Stroke Trials (HERMES) meta-analysis was 68 years. $^{2}$

Hospital mortality and mortality at 90 days were nonsignificantly higher in patients with premorbid mRS 4 compared with premorbid mRS 3. This difference is probably not significant due to the low number of patients with premorbid mRS 4 in our cohort $(n=25)$. A possible explanation is that treatment in patients with premorbid mRS 4 might be terminated earlier compared with patients with premorbid mRS 3 .

Successful recanalization was the most powerful predictor of good outcome (OR, 7.11; 95\% CI, 1.73-49.90; $P=.0171$ ). Furthermore, increasing stroke severity (high NIHSS score) and increasing infarct size (low ASPECTS) were associated with lower chances of achieving good outcome in our cohort. This finding has been previously described by Hui et al. ${ }^{8}$ Although both parameters were statistically independent predictors, they might nevertheless be related to the occlusion site because proximal occlusions are usually associated with worse outcome compared with distal occlusions. ${ }^{9}$ In our cohort, M2 occlusions were more frequent in patients with good outcome, and ICA occlusions were more frequent in patients with poor outcome.

Our study has limitations, mainly due its retrospective nonrandomized design. There might be a selection bias because patients with stroke with premorbid mRS 3 and 4 not undergoing MT were not included in this study. Because we did not have a control group, it is not possible to determine the benefit of MT compared with best medical care. MT may possibly have little benefit in patients with premorbid mRS 3 and 4 . Also, only a small group of 25 patients with premorbid mRS 4 were analyzed in this study. Moreover, using the $\mathrm{mRS}$ for prestroke assessment is controversial because the mRS is primarily designed to assess posttreatment clinical status. Fearon et $\mathrm{al}^{10}$ have reported that interobserver reliability and validity of premorbid mRS are limited. In some cases, assessing the premorbid status is not even possible because of missing or incorrect information. Nonetheless, mRS is the most frequently used measure to assess the premorbid status of patients with acute stroke.

\section{CONCLUSIONS}

Overall, good clinical outcome, defined as unchanged disability, is less frequent in premorbid mRS 3 and 4 compared with patients with premorbid mRS $0-2$. Nevertheless, about $20 \%$ of the patients return to their premorbid mRS, which may justify endovascular treatment. Because we did not have a control group, it is not possible to determine the benefit of MT compared with best medical care. MT may possibly have little benefit in patients with premorbid mRS 3 and 4 . The most important predictor of good outcome is successful recanalization.

Disclosures: Johannes Pfaff-UNRELATED: Travel/Accommodations/Meeting Expenses Unrelated to Activities Listed: Stryker, MicroVention. Christian HerwehUNRELATED: Consultancy: Brainomix. Simon Nagel—UNRELATED: Consultancy: Brainomix; Payment for Lectures Including Service on Speakers Bureaus: Medtronic, Pfizer, Bayer, Boehringer Ingelheim. Peter A. Ringleb-UNRELATED: Consultancy: Boehringer Ingelheim, Comments: Advisory Board member; Payment for Lectures Including Service on Speakers Bureaus: Boehringer Ingelheim, Bayer, Daiichi Sankyo, Pfizer, Comments: lecture fee, travel support. Martin Bendszus-UNRELATED: Board Membership: Data and Safety Monitoring Board for Vascular Dynamics, Guerbet, Boehringer Ingelheim; Consultancy: Codman, Roche, Guerbet, Boehringer Ingelheim, B. Braun; Grants/Grants Pending: DFG, Hopp Foundation, Novartis, Siemens, Guerbet, Stryker, Covidien*; Payment for Lectures Including Service on Speakers Bureaus: Novartis, Roche, Guerbet, Teva Pharmaceutical Industries, Bayer, Codman. Markus A. Möhlenbruch—UNRELATED: Board Membership: Codman; Consultancy: Medtronic, MicroVention, Stryker; Grants/Grants Pending: Balt, MicroVention*; Payment for Lectures Including Service on Speakers Bureaus: Medtronic, MicroVention, Stryker. *Money paid to the institution.

\section{REFERENCES}

1. Swieten JC van, Koudstaal PJ, Visser MC, et al. Interobserver agreement for the assessment of handicap in stroke patients. Stroke 1988; 19:604-07 CrossRef Medline

2. Goyal M, Menon BK, van Zwam WH, et al. Endovascular thrombectomy after large-vessel ischaemic stroke: a meta-analysis of individual patient data from five randomised trials. Lancet 2016; 387:1723-31 CrossRef Medline 
3. Albers GW, Marks MP, Kemp S, et al. Thrombectomy for stroke at $\mathbf{6}$ to 16 hours with selection by perfusion imaging. N Engl J Med 2018; 378:708-18 CrossRef Medline

4. Powers WJ, Rabinstein AA, Ackerson T, et al; American Heart Association Stroke Council. 2018 Guidelines for the Early Management of Patients with Acute Ischemic Stroke: A Guideline for Healthcare Professionals from the American Heart Association/American Stroke Association. Stroke 2018;49:e46-110

5. Wilson A, Bath PM, Berge E, et al. Understanding the relationship between costs and the modified Rankin Scale: a systematic review, multidisciplinary consensus and recommendations for future studies. Eur Stroke J 2017;2:3-12 CrossRef Medline

6. Dewilde S, Annemans L, Peeters A, et al. Modified Rankin scale as a determinant of direct medical costs after stroke. Int J Stroke 2017; 12:392-400 CrossRef Medline
7. Knoflach M, Matosevic B, Rücker M, et al. Functional recovery after ischemic stroke: a matter of age- data from the Austrian Stroke Unit Registry. Neurology 2012;78:279-85 CrossRef Medline

8. Hui FK, Obuchowski NA, John S, et al. ASPECTS discrepancies between CT and MR imaging: analysis and implications for triage protocols in acute ischemic stroke. J Neurointerv Surg 2017;9: 240-43 CrossRef Medline

9. Behme D, Kowoll A, Weber W, et al. M1 is not M1 in ischemic stroke: the disability-free survival after mechanical thrombectomy differs significantly between proximal and distal occlusions of the middle cerebral artery M1 segment. J Neurointerv Surg 2015;7:559-63 CrossRef Medline

10. Fearon P, McArthur KS, Garrity K, et al. Prestroke modified Rankin Stroke Scale has moderate interobserver reliability and validity in an acute stroke setting. Stroke 2012;43:3184-88 CrossRef Medline 